\title{
A IMPORTÂNCIA DO RECONHECIMENTO NO MUNDO DO TRABALHO DA PESSOA COM DEFICIÊNCIA PARA A (RE)CONSTRUÇÃO DA IDENTIDADE SOCIAL A PARTIR DE AXEL HONNETH
}

\begin{abstract}
Álvaro dos Santos Maciel *
RESUMO

Visando ao combate à discriminação e tutela trabalhista das minorias, a pesquisa aborda o processo de reconhecimento jurídico-social das pessoas com deficiência na perspectiva da teoria das esferas do reconhecimento proposta por Axel Honneth e de que modo o mundo do trabalho colabora com esta construção. A problemática consiste em identificar, a partir das esferas do reconhecimento social, quais são os mecanismos de inclusão efetiva para que haja o reconhecimento social de modo a concretizar a isonomia. Conclui-se que a Lei de Cotas ainda apresenta desafios e perspectivas que conduzam à inclusão real como condição ao reconhecimento integral dos indivíduos.
\end{abstract}

Palavras-chave: reconhecimento jurídico-social; trabalho; pessoas com deficiência; Axel Honneth.

\section{THE IMPORTANCE OF RECOGNITION IN THE WORLD OF WORK OF DISABLE PEOPLE FOR THE (RE) CONSTRUCTION OF SOCIAL IDENTITY ACCORDING TO AXEL HONNETH}

\begin{abstract}
Aiming to combat discrimination and labor protection for minorities, the research aims the legal-social recognition of disabled people in the perspective of the theory of recognition spheres proposed by Axel Honneth and how the world of work collaborates with this construction. The problem consists in identifying, based on theories of social recognition, which are the mechanisms of effective inclusion to achieve social recognition and isonomy. It is concluded that the Quota Law still presents challenges and perspectives that lead to real inclusion as a condition for the full recognition of individuals.
\end{abstract}

Key words: legal and social recognition; job; disabled people; Axel Honneth.

\section{INTRODUÇÃO}

\footnotetext{
* Doutor em Ciências Jurídicas e Sociais pela Universidade Federal Fluminense (UFF, 2017) com estágio sanduíche na Universidade de Lisboa (UL, 2016), Mestre em Ciências Jurídicas pela Universidade Estadual do Norte do Paraná (UENP, 2010), com especialização em Direito Civil e Processual Civil pela Universidade Estadual de Londrina (UEL, 2007). Graduado em Direito pela Universidade Norte do Paraná (2004). Bolsista pela CAPES (2013-2017), Pesquisador visitante pela Universidade de Lisboa (2016). Advogado e Professor de Graduação e Pós-Graduação, com experiência em cargos de gestão, núcleos laboratoriais e prática jurídica. Atua principalmente nos seguintes temas: Direito do Trabalho, Processo do Trabalho e Direitos Humanos.
} 
A diversidade, o pluralismo e o crescente aumento de demandas político-jurídicas sobre identidade e autonomia das pessoas com deficiência são os substratos que justificam o aprofundamento dos preceitos da teoria do reconhecimento (anerkennung) ${ }^{2}$ e, por isso são demandadas análises de matrizes críticas que ultrapassem a identificação cognitiva de um indivíduo ao explorarem a questão da atribuição de valores positivos que promovam a diversidade na construção cultural de normalidade, até como forma de combate à discriminação, incluindo, consequentemente, transformações no plano do mundo do trabalho com tutela trabalhista das minorias.

A compreensão da configuração acerca da participação efetiva da pessoa com deficiência no mercado de trabalho assume um lugar de destaque e levanta questões como identidade, preconceito, discriminação, estigma, estereótipos, invisibilidade e inclusão elenca como referencial teórico a teoria do reconhecimento iniciada por Hegel, ainda durante sua juventude, como um fundamento potencialmente explicativo da nova realidade das relações sociais e o cotidiano das pessoas com deficiência na relações de trabalho. Hegel entende que os conflitos intersubjetivos são parte do processo de reconhecimento recíproco necessários à formação da autoconsciência individual e, dessa maneira, a luta por reconhecimento está na base dos conflitos sociais.

Nesse processo, três esferas do reconhecimento em sua tríplice tipologia progressiva, geram diferentes dimensões de autorrealização e devem ser abordadas: amor, direito e solidariedade (Honneth, 2003, p. 119-122), como a seguir será explicitado.

Sabe-se que produzir uma crítica ainda se trata de um fator complexo haja vista a tarefa de definir o que é crítica e que postura um crítico deve manter em relação ao objeto a ser criticado. Para Gil (2008, p. 37), um estudo elaborado encontra dificuldades na formulação de críticas científicas. Pois identificar o problema com eficiência é uma capacidade que revela a genialidade científica.

$\mathrm{Na}$ presente pesquisa, sem pretensão de esgotar o estudo, porém com intenção de colaborar com o aprimoramento crítico, se faz necessária a resolução do problema que pode ser assim explicitado:

A pessoa com deficiência, como qualquer outro indivíduo deve estar plenamente inserida na sociedade como forma de alcançar a reconhecimento social, ou seja, o

\footnotetext{
${ }^{2} \mathrm{O}$ conceito filosófico de reconhecimento significa a atribuição de um valor positivo a uma pessoa, algo próximo do que entendemos por respeito (ASSY; FERES JÚNIOR, 2006, p. 705).
} 
reconhecimento na família, no direito e na sociedade. Entretanto, em que pese haja o reconhecimento familiar e, muitas vezes sejam criadas leis que determinam a inclusão destes atores sociais, como por exemplo no mundo do trabalho (Lei de Cotas, Estatuto da Pessoa com Deficiência), muitas vezes, a pessoa com deficiência não tem o reconhecimento social ou mesmo individual almejado por conta de estigmas e preconceitos que acabam gerando impacto na identidade individual e coletiva do grupo. Vê-se, que há vezes em que as pessoas com deficiência são inseridas pelas cotas, porém, o mundo do trabalho não desencadeia o desenvolvimento de sua "auto estima" diante de tamanhos estigmas. Logo, a partir das esferas do reconhecimento social, quais são os mecanismos de inclusão efetivos para que haja o reconhecimento social pleno e, deste modo, concretizar a isonomia em prol das pessoas com deficiência?

A justificativa do presente estudo consiste em demonstrar que o reconhecimento social pleno da pessoa com deficiência passa por esferas, incluindo o mundo do trabalho. Todavia, muitas vezes, as pessoas com deficiência, em que pese tenham seus direitos respeitados - no que tange reserva de vagas; não têm a dignidade respeitada haja vista preconceitos e estigmas de toda sorte que lhe são direcionados mesmo após o emprego alcançado. Isso é capaz de gerar impactos na justiça social, transversal e na dignidade humana dos indivíduos. Trata-se de um tema atual, haja vista que urge pensar formas de viver a inclusão democrática em prol de concretizar igualdade num contexto de distintas concepções de reconhecimento, portanto, de justiça.

Dessa forma, para sequenciar o principal objetivo desta pesquisa que é apresentar, fazendo, em muitos momentos, apelo à intuição em referências do Direito e da Sociologia, as esferas do reconhecimento de uma pessoa para que se possa promover a (re)construção da identidade da pessoa com deficiência no mundo do trabalho.

Para tanto, opta-se como marco teórico os ensinamentos do filósofo e sociólogo alemão Axel Honneth ${ }^{3}$ que em sua obra intitulada "Luta por reconhecimento: a gramática moral dos conflitos sociais” (2003)[1992], realiza uma análise das esferas do reconhecimento suscetível de aplicação empírica da teoria sociológica do reconhecimento de movimentos sociais e outros conflitos intersubjetivos que fazem parte do processo de evolução social ${ }^{4}$.

\footnotetext{
${ }^{3}$ Honneth não aborda especificamente a situação das pessoas com deficiência, mas pesquisadores dos estudos sobre deficiência (disability studies) utilizam suas teorias, tal como Abberley (2002, pp. 128-130).

${ }^{4}$ Para a realização deste trabalho, adota-se o entendimento majoritário de que esta obra é o ponto de partida para o entendimento acerca das interações decorrentes da cultura social a partir do reconhecimento das identidades dos sujeitos e vice-versa, contrariando, portanto, uma específica corrente da teoria crítica da sociedade que
} 
A busca de uma satisfatória objetividade científica e sistematicidade na análise do fenômeno estudado impõem respeito a um conjunto de procedimentos ou métodos de observância racionais que permitam reflexões que descubram e demonstrem a efetiva dinâmica do objeto em análise. Para investigar o tema proposto, o presente estudo faz uso do método de abordagem hipotético-dedutivo ${ }^{5}$. Preliminarmente, cabe aferir que os aspectos que este método tem em comum para com o método dedutivo reportam-se ao procedimento racional que transita do geral para o particular e, com o método indutivo, o procedimento experimental. A questão central dessa metodologia é a crítica tanto para com a metodologia indutiva como dedutiva, visto que a ciência não é capaz de estabelecer verdades, mas, sim, possibilidades.

\section{PELO RECONHECIMENTO SOCIAL: MARCOS TEÓRICOS}

Honneth (2003) adota como ponto de partida para o desenvolvimento de sua tese acerca da luta por reconhecimento, os ensinamentos do período da juventude do filósofo alemão Friedrich Hegel que se debruçou sobre uma incompleta teoria da intersubjetividade. Dessa forma, acerca dos estudos hegelianos, Honneth destaca:

\footnotetext{
$\mathrm{Na}$ primeira parte de sua análise filosófica, o procedimento metodológico de Hegel consiste em reconstruir o processo de formação do espírito subjetivo, ampliando-o passo a passo de modo que abranja as condições necessárias da autoexperiência da consciência individual; o resultado desse procedimento reconstrutivo deve esclarecer quais experiências, repletas de exigências, um sujeito precisa ter feito no todo antes de estar em condições de conceber-se a si mesmo como uma pessoa dotada de 'direitos' e, nessa medida, poder participar então na vida institucionalmente regulada de uma sociedade, isto é, no espírito 'efetivo' (Honneth, 2003).
}

Para Hegel, o reconhecimento social de um indivíduo apenas ocorreria quando quem o reconhece também possui seu próprio valor honrado por ele, ou seja, quando quem reconhece o valor do outro se vê reconhecido e respeitado pelo outro, razão pela qual a reciprocidade seria condição essencial para o reconhecimento social. Deste modo, exemplifica no ensaio "Senhorio e Escravo" (parte integrante da obra "Fenomenologia do Espírito" de sua autoria),

entende que Honneth faz uma guinada para análise de sociologia empírica apenas a partir de sua obra "Trabalho e reconhecimento: Tentativa de uma redefinição"(2008), que igualmente será abordada na sequência deste estudo.

5 A Karl Popper (2007) é tributado o desenvolvimento desse modelo metodológico, especialmente em sua obra “A Lógica da Pesquisa Científica". Consoante Gil (2008, p. 13), nos círculos neopositivistas chega a ser considerado como o único método rigorosamente lógico. 
que o senhor de escravos detinha essa condição porque se enxergava dessa forma nos olhos de seu escravo e o escravo nos olhos do seu senhor (ASSY; FERES JR, 2006, p. 705-706). Aqui pode-se reportar às análises das abordagens pós-modernistas da deficiência apresentadas no tópico 1.3, onde tem-se que a deficiência é vista como um produto da medicina que a classifica como anomalia social e os indivíduos acabam por se autoperceberem e se autodefinirem nestes exatos termos médicos (TREMAIN 2005), numa espécie de autopercepção a partir do julgamento externo conhecido - "mirror effect" (HARRIS \& ENFIELD 2003, p.17).

Numa análise metafísica, Hegel entende que a definição dos indivíduos em um ambiente coletivo define-se pelo olhar do outro a partir de laços formados no meio social, e aponta três relações de reconhecimento - o amor, o direito e a eticidade - como valores que instrumentalizam a afirmação recíproca das pessoas enquanto sujeitos autônomos e individualizados, sendo que, para a formação de suas identidades, os sujeitos seriam transcendentalmente compelidos a entrar em uma espécie de conflito intersubjetivo uns com os outros, em busca de reconhecimento de sua autonomia (HONNETH, 2003, p. 121).

Para Honneth, as teorias sobre reconhecimento afirmadas por Hegel evoluem como numa espiral ascendente, eis que vai da formação da autoconsciência e do reconhecimento das pessoas, ao movimento de conflito entre os sujeitos chegando a um modelo de confronto de maneira idealista, metafísica; o que pode ser complementado pelas teorias do "interacionismo simbólico" propostas pelo filósofo americano George Herbert Mead. ${ }^{6}$ Os estudos de Mead (1973) dedicaram-se à compreensão do processo de sociabilidade e a inserção do sujeito na comunidade a que pertence, já que o indivíduo integrado à realidade social possui um self cuja manifestação se dá na afirmação de si ou na identificação do sujeito com o contexto coletivo, o que pode assegurar então, a sociabilidade do indivíduo, a incorporação das atitudes sociais e a constituição de uma sociedade plural. O self só pode ser inteiramente desenvolvido quando as pessoas tornam-se membros de uma comunidade e agem consoante as atitudes comuns desta comunidade, por conseguinte, não advém do nascimento, e sim do processo da experiência e da atividade social. Em síntese, o fio condutor da obra é que o sujeito se origina tão somente a partir do social, sendo o social que o constitui.

\footnotetext{
${ }^{6}$ Os escritos de Mead podem ser vistos como uma tradução da teoria hegeliana da intersubjetividade numa linguagem teórica pós-metafísica, ou seja, demonstram elementos de um conceito de intersubjetividade que visa à superação da metafísica moderna para tornar-se uma espécie de psicologia social com bases empíricas ao atribuir uma inflexão materialista à teoria hegeliana da luta por reconhecimento (HONNETH, 2003).
} 
Deste modo, Honneth (2003, p.125 et. seq.) utiliza a obra de Mead (1973) para corroborar com a ideia de que a inserção do indivíduo na sociedade organizada dentro do domínio de experiências de cada sujeito envolvido ou incluído no todo é a base para a plenitude do desenvolvimento da identidade do indivíduo, ou seja, a formação da identidade humana é decorrente de uma relação de interação entre sujeitos com proposta de reconhecimento mútuo que, ao assumirem as normas sociais de ação podem alcançar a identidade de um membro socialmente aceito em sua coletividade. Eis que:

\footnotetext{
Ao aprender a generalizar em si mesmo as expectativas de um número cada vez maior de parceiros de interação, a ponto de chegar à representação das normas sociais de ação, o sujeito adquire a capacidade abstrata de poder participar nas interações normativamente reguladas de seu meio; pois aquelas normas interiorizadas lhe dizem quais são as expectativas que pode dirigir legitimamente todos os outros, assim como quais são as obrigações que ele tem de cumprir justificadamente em relação a eles (Idem, p.135-136).
}

Para Mead (1973, p. 204ss.), um indivíduo se sente dotado de dignidade quando é reconhecido como um membro do grupo em decorrência de direitos. O indivíduo se torna consciente do valor social de sua identidade por meio de um autorrespeito caracterizado pela atitude positiva do sujeito consigo cuja gradatividade decorre da confirmação pelos parceiros ("outro generalizado"), ou seja, quanto maior for esse contingente, maiores serão as quantidades de normas internalizadas e mais abrangente será o nível de reconhecimento recíproco entre indivíduo e sociedade na confirmação de suas particularidades por meio de uma autoestima ("eticidade"). Mead entende existir para fins de assentimento solidário, um vínculo entre a autorrealização e a experiência do trabalho social útil, e seus métodos para compreender a eticidade hegeliana não seriam os mais adequados em razão da experiência do trabalho socialmente útil depender das finalidades da própria coletividade e da sua concepção interna de vida digna ("vida boa"), que se sujeitam aos valores culturais e morais da coletividade, bem como sua capacidade de promover ou não o alargamento dos horizontes normativos (Honneth, 2003, p. 151 ss).

Deste modo, tanto as teorias de Mead, como as de Hegel, ao consignarem cada qual a sua maneira, que os atores sociais necessitam ser reciprocamente reconhecidos a fim de alcançar autorrealização e autonomia individual, apresentaram contributos para que Honneth com argumentos complementares formulasse uma teoria representativa do reconhecimento como categoria moral fundamental por meio de três formas de reconhecimento recíproco: primeiro, a esfera da dedicação emotiva (amor); segundo, a esfera do reconhecimento jurídico 
(ou de direito); em terceiro, a solidariedade (ou estima social), apresentando uma teoria representativa do reconhecimento como categoria moral fundamental.

\section{AS ESFERAS DO RECONHECIMENTO SOCIAL A PARTIR DE AXEL HONNETH}

Postos os marcos teóricos que inspiraram as teorias de Honneth, é importante descrever as três esferas ou formas de reconhecimento propostas pelo autor, pois permitirá entender as "as limitações morais subjacentes à integração social" (FRASER; HONNETH, 2003, p. 185) das pessoas com deficiência e assim atender à problemática da discussão do reconhecimento destes atores no mercado de trabalho.

Enquanto na esfera do amor e das relações afetivas, o reconhecimento se liga ao desenvolvimento psíquico da personalidade, teorias a que esta pesquisa não se destina, mas visando um maior entendimento se faz uma abordagem a seguir ainda que de modo tangencial. Nas duas outras esferas, do direito e da solidariedade, vê-se claramente o quadro moral que também pode gerar conflitos sociais já que se baseiam em critérios socialmente generalizados e, por conseguinte, mais se vinculam à temática estudada, eis que o reconhecimento das pessoas com deficiência está vinculado à participação plena na vida cultural da comunidade, seja por meio das reivindicações de grupos particulares junto às esferas jurídicas, seja quanto às reivindicações que remetem à sociedade civil, seja por respeito às liberdades formais e materiais, ou ainda por quaisquer mecanismos que propriciem a valorização da honra e da dignidade.

\subsection{A tríplice forma progressiva das esferas de reconhecimento}

\subsubsection{A primeira esfera de reconhecimento:}

A primeira esfera de reconhecimento resulta na formação de autoconfiança e acontece no plano psicológico dos afetos, inicialmente diagnosticada por Hegel no amor compreendido como relação de natureza íntima ou erótica entre um homem e uma mulher. Honneth (2003, p. 159 ss), entretanto, amplia o campo de análise dessa esfera para as questões de amizade e questões familiares ambientadas no meio social, e busca na abordagem empírica do pediatra psicanalista inglês Donald W. Winnicott os substratos por ele chamados de "condições 
suficientemente boas" da socialização de crianças em seus primeiros meses de vida com suas mães. Para Winnicott (1984), o primeiro estágio do amadurecimento infantil é aquele em que há uma "dependência absoluta" entre mãe e filho, momento em que há uma espécie de "serum simbiótico", representando uma verdadeira fusão entre os parceiros de interação. Honneth (2003, p. 163 ss) corrobora e afirma que "o apoio do ego materno facilita a organização do ego do bebê. Com o tempo, o bebê torna-se capaz de afirmar sua própria individualidade, e até mesmo experimentar um sentimento de identidade pessoal". Conclui que "o reconhecimento nessa esfera designa o duplo processo de uma liberação e ligação emotiva simultâneas da outra pessoa", ou seja, identifica duas etapas do amadurecimento infantil, que se implementam por meio da cooperação intersubjetiva entre mãe e filho. Dessa forma, iniciase o segundo estágio do amadurecimento, no qual os parceiros de interação (mãe e filho) saem do estado de "dependência absoluta" ("ser-um simbiótico"), e passam, segundo Winnicott a um momento de "dependência relativa" ("ser-em-si-mesmo em um outro"), no qual ambos iniciam um processo de compreensão enquanto sujeitos com parcela de autonomia e independentes entre si. Neste estágio não mais se enxergam como uma extensão de seus próprios corpos, pois notam que podem sobreviver sem o estado simbiótico inicial (Ibidem, p. $167-168)^{7}$. Uma relação de êxito entre mãe e filho torna-se um padrão de interacionismo, e a recorrência na vida adulta pode ser um indicador positivo nas relações de autoconfiança com outros seres humanos. Ademais, supõe-se que esteja no amor o cerne estrutural da eticidade, haja vista que tão somente essa ligação simbioticamente alimentada é capaz de criar uma medida de autoconfiança individual, que é a base indispensável para a participação autônoma na vida pública sendo representada pelo duplo processo de ligação e liberação emotiva entre os indivíduos, ou seja, equilíbrio entre dedicação e afirmação da autonomia afetiva (Ibidem, p. 178).

Se desrespeitada esta primeira esfera do reconhecimento social, na prática estará prejudicada a formação da autoconfiança do indivíduo por intermédio das relações emotivas, consistente na "capacidade de coordenação autônoma do próprio corpo" (Ibidem, p. 215), razão pela qual o autor identifica esse desrespeito na figura dos maus-tratos, do abuso, da

\footnotetext{
${ }^{7}$ Acerca do segundo estágio do Amadurecimento infantil empiricamente estudado por Winnicott e abordado pela obra de Honneht, a análise de Mattos (2006, P. 90) é no sentido de que neste momento "a criança começa a perceber a distinção entre o seu corpo e o ambiente, bem como passa a compreender os sinais de que suas necessidades serão atendidas futuramente. A fase de simbiose se esgota quando ambos obtêm para si um pouco de independência. Nesse processo, a criança tem a sensação de que a mãe a abandonou para cumprir suas obrigações cotidianas. Com isso, ela irá se voltar contra a mãe por meio de atos agressivos. É a partir dessa experiência que ela toma consciência de que sua mãe é um ser com existência própria, distinta da sua."
} 
tortura, da alienação, do controle da pessoa sobre o próprio corpo, e demais ofensas que possam ameaçar o componente da personalidade humana correspondente à integridade física do sujeito. Esse insulto, tem o estupro e a tortura como seus exemplos mais latentes, produz um dano psicológico superior à dor física, uma "morte psicológica", que se converte em "perda da autoconfiança, estranhamento em relação ao mundo e insegurança no contato com as outras pessoas. Em suma, ela é ferida em sua autoimagem” (Ibidem, p. 214-215). Com relação às pessoas com deficiência, observa-se que esta forma de desrespeito se fez presente em vários períodos históricos haja vista que em razão de características corporais, as pessoas com deficiência eram expostas por suas próprias famílias, abandonadas, segregadas, alvos de eugenia, e foram objetificadas ou tratadas como seres inumanos ou quase-humanos até meados do século XX (ALBRECHT; SEELMAN; BURY, 2001; GUGEL, 2008; SILVA, 1987; BARBOSA-FOHRMANN; KIEFER, 2016). Ademais, no que tange ao controle da pessoa sobre si mesma, pode-se citar ainda a recente revogação no Brasil do instituto da incapacidade civil de determinadas deficiências mentais que deflagrava desrespeito à autonomia da pessoa já que, em alguns casos, podia exprimir a sua vontade normalmente, o que deu azo ao surgimento do instrumento denominado "tomada de decisão apoiada", seguindo na direção de legislações mundiais avançadas na temática do reconhecimento civil destes indivíduos. Ferrajoli (2009, p.22) enfatiza que muitas vezes a capacidade e a cidadania são barreiras que dificultam o acesso aos direitos fundamentais, especialmente à igualdade de oportunidades. Agora, a legislação, neste quesito, busca privilegiar o espaço de escolha e controle das pessoas com deficiência mental sobre si mesmas na medida em que podem constituir, com base em vontade própria, uma rede de sujeitos baseada na confiança para lhes auxiliarem nos atos da vida.

Foi a partir da segunda metade do século XX que se deu o início o processo de reconhecimento formal desse grupo social nos moldes preconizados por Honneth, em que as atitudes positivas desta primeira esfera do reconhecimento, enquanto valorização das bases

\footnotetext{
8 Trata-se de um instituto novo introduzido pelo art. 116 do Estatuto da Pessoa com Deficiência (Lei nº13.146/2015) que, não obstante não constitua cópia de outras legislações, guarda semelhança com a amministrazione di sostegno italiana e com o contrato de representação instituído pela British Columbiam canadense. Foi criado para atender a orientação geral da CDPD, especialmente ao disposto no art. 12. - "Os Estados Partes tomarão medidas apropriadas para prover o acesso de pessoas com deficiência ao apoio que necessitarem no exercício de sua capacidade legal". Neste novo sistema da tomada de decisão apoiada, por iniciativa da pessoa com deficiência são nomeadas pelo menos duas pessoas idôneas "com as quais mantenha vínculos e que gozem de sua confiança, para prestar-lhe apoio na tomada de decisão sobre atos da vida civil, fornecendo-lhes os elementos e informações necessários para que possa exercer sua capacidade." (art. 1783-A, Código Civil). Informações detalhadas sobre esta inovação legislativa e social podem ser encontradas nos estudos realizados por MENEZES (2016) e REQUIÃO (2016).
} 
psicológicas, para que as pessoas pudessem, posteriormente, desenvolver atitudes de autorrespeito. Foi quando a segregação deixou de ser a principal medida social relativa à deficiência, e a reabilitação passou a ser um importante instrumento na melhoria do bemestar, já que até então, não lhes era garantida a possibilidade de manter o controle sobre o seu próprio corpo, uma vez que nas instituições eram submetidas a regimes disciplinares que tolhiam sua liberdade, e aos cuidados na forma em que a instituição julgasse por bem oferecer (BONFIM, 2009). ${ }^{9}$

Em síntese, consoante Honneth, o processo de individualização se inicia nas relações próximas de afeto da família e de amizades constituindo a base da relação social do sujeito, é o locus em que o amor simbiótico predomina, mas que é gradativamente substituído pelo afeto recíproco. Então, a seguir, há uma universalização da gramática moral do afeto familiar por meio de reconhecimento fundamentado no respeito cognitivo gerado pelas relações jurídicas, em que os indivíduos passam a aceitar um ao outro como sujeitos de direitos.

\subsubsection{A segunda esfera de reconhecimento:}

Tem-se, deste modo, que a segunda forma de reconhecimento é a jurídica, que desenvolve uma contribuição para a formação do autorrespeito do indivíduo. Neste enfoque, Honneth (2003, p. 179-181) ressalta que as teorias de Hegel e de Mead foram capazes de identificar que os indivíduos somente se compreendem como sujeitos de direitos e concebemse merecedores da mesma proteção jurídica que os demais, quando o sujeito se torna dependente dos princípios morais universais no conceito hegeliano original, ou quando, por intermédio do papel social do indivíduo pela divisão do trabalho no meio social, conhecem as obrigações que devem ser assumidas frente aos demais parceiros de interação social.

\footnotetext{
${ }^{9}$ É interessante apontar o destaque realizado por Bonfim (2009, p. 73-74) ao estender-se sobre (Arneil 2009, p. 218- 242) que apresenta a complexidade do tema quando se analisa o "reconhecimento de pessoas com deficiências tão severas que os impedem, mesmo que seja proporcionado o cuidado necessário, de participar da vida social. Pessoas com deficiências cognitivas sérias ou com lesões ou transtornos mentais são casos emblemáticos, mormente quando não apresentam a racionalidade demandada por algumas correntes filosóficas para serem considerados como 'homens'. Apesar de algumas tentativas de ressignificar a deficiência na teoria social contemporânea, ainda não foram apresentadas respostas satisfatórias sob a ótica do reconhecimento. De acordo com o modelo teórico honnethiano, o reconhecimento intersubjetivo dessas pessoas situa-se na primeira etapa, correspondente ao atendimento de suas necessidades físicas básicas, que pode ser apoiada pelo Estado, por meio de benefícios assistenciais. A passagem para a segunda etapa fica prejudicada porque essa transição pressupõe que o sujeito seja detentor de autonomia individual, na forma preconizada pela tradição kantiana. Nesse caso, tanto as pessoas com limitações físicas severas como aquelas com deficiências cognitivas sérias vêem-se impedidos de alcançar tal etapa do reconhecimento, pois se encontram impossibilitados de exprimir sua vontade de forma racional."
} 
Entretanto, Honneth (2003, p. 182) considera que não será o status social prevalente nas sociedades tradicionais e nem mesmo a função social do indivíduo na moderna divisão do trabalho que determinarão a obediência às normas jurídicas ou mesmo o reconhecimento recíproco entre os sujeitos sociais, ao contrário, os parceiros de interação de um grupo ao se considerarem livres e iguais reconhecem-se reciprocamente como sujeitos de direitos, capazes de decidir com autonomia individual sobre as normas morais.

A teoria honnethiana formula suas bases a partir da distinção entre as sociedades tradicionais - em que o reconhecimento é ancorado na posição que o indivíduo ocupa na sociedade; e as sociedades modernas - em que o sistema jurídico deve propiciar um reconhecimento geral por meio de mecanismos que garantam o direito fundamental à liberdade; o direito à participação de todos na esfera pública; e os direitos que possibilitem o bem-estar de todos os indivíduos da sociedade. Dessa maneira, ao garantir maior efetividadade aos direitos fundamentais, as relações jurídicas devem priorizar as características universais do ser humano pautadas na igualdade e assim ratifica os ensinamentos de Hegel ao afirmar:

\begin{abstract}
(...) determinações da pessoa de direito só assume a forma de reconhecimento do direito quando ela se torna dependente historicamente das premissas dos princípios morais universalistas. Pois, com a passagem para a modernidade, as categorias pós-convencionais, que já antes foram desenvolvidas na filosofia e na teoria política, penetram no direito em vigor, submetendo-o à pressões de fundamentação associadas à ideia de um acordo racional acerca de normas controversas; o sistema jurídico precisa ser entendido de agora em diante como expressão dos direitos universalizáveis de todos os membros da sociedade, de sorte que ele não admita mais, segundo suas pretensão, exceções e privilégios (Ibidem, p. 181).
\end{abstract}

$\mathrm{Na}$ sociedade contemporânea, observa-se o aumento de pretensões jurídicas individuais e coletivas que decorre da pressão de uma luta por reconhecimento baseado na extensão das propriedades universais de uma pessoa moralmente imputável (Ibidem, p. 189).

A evolução da ciência do Direito fez os direitos subjetivos desdobrarem-se em direitos liberais, direitos políticos, de participação, direitos sociais, de bem-estar e de solidariedade como resultado de uma luta por reconhecimento jurídico. ${ }^{10}$ Como fundamento histórico, é válido destacar os apontamentos formulados pelo jurista tcheco Karel Vasak, citados por

\footnotetext{
${ }^{10}$ Para explicar esta evolução, a teoria honnethiana (2003, p. 190) vale-se dos estudos do sociólogo britânico Thomas H. Marshall que em sua obra "Sociology at the Crossroads" (1963), compiladas no Brasil por meio de ensaios incluídos na obra "Cidadania, Classe Social e Status" (1967) demonstra que a ampliação das pretensões jurídicas universais no meio social adveio de um longo processo histórico de luta pela incorporação de novas demandas jurídicas deflagradas pelas classes menos favorecidas, o que corresponde a uma luta por reconhecimento jurídico.
} 
Marmelstein (2008) ao apresentar como o Direito apresenta os direitos conquistados por dimensões decorrentes da luta por reconhecimento:

\footnotetext{
a) primeira geração dos direitos seria a dos direitos civis e políticos, fundamentados na liberdade (liberté), que tiveram origem com as revoluções burguesas;

b) a segunda geração, por sua vez, seria a dos direitos econômicos, sociais e culturais, baseados na igualdade (égalité), impulsionada pela Revolução Industrial e pelos problemas sociais por ela causados;

c) por fim, a última geração seria a dos direitos de solidariedade, em especial o direito ao desenvolvimento, à paz e ao meio ambiente, coroando a tríade com a fraternidade (fraternité), que ganhou força após a Segunda Guerra Mundial, especialmente após a Declaração Universal dos Direitos Humanos, de 1948.
}

A apresentação de Honneth ao analisar a evolução do Direito detém proximidade com as teorizações realizadas pelo filósofo político e jurista italiano Norberto Bobbio por considerar que os direitos podem ser vistos como a característica definidora desse tempo que veio a intitular de "Era dos direitos" em sua obra igualmente assim denominada (ALBORNOZ, 2011, p. 39).

Bobbio (1992, p. 5) compreende que os direitos do homem, por mais fundamentais que sejam, são direitos históricos, ou seja, "nascidos em certas circunstâncias, caracterizadas por lutas em defesa de novas liberdades contra velhos poderes, e nascidos de modo gradual, não todos de uma vez e nem de uma vez por todas", e assim identifica as dimensões de direitos reconhecidos por ele como: I) “primeira geração” em que discorre acerca das liberdades, sendo a liberdade religiosa a origem do processo de afirmação de direitos humanos, e seguidamente as liberdades civis, da luta dos parlamentos contra o absolutismo; a liberdade política e social, advindas do nascimento, crescimento e amadurecimento do movimento dos trabalhadores assalariados, dos camponeses despossuídos de terras, dos pobres que exigem dos poderes públicos o reconhecimento da liberdade pessoal e das liberdades negativas; ao lado, os II) direitos de "segunda geração" com ênfase aos direitos sociais, em que o Estado assistencialista oferece aos indivíduos proteção do trabalho contra o desemprego, os primeiros rudimentos de instrução contra o analfabetismo, a assistência à deficiência, ao desamparo e à velhice; III) os direitos de "terceira geração" encampados por direitos novos como "o reivindicado pelos movimentos ecológicos: o direito de viver num ambiente não poluído". Além disso, Bobbio ainda previu IV)direitos de "quarta geração" referentes às consequências da pesquisa biológica, manipulações do patrimônio genético e bioética. 
Posto isso, reconhecer juridicamente o indivíduo, e precisamente as pessoas com deficiência implica em afirmar toda a gama de direitos conquistados historicamente e assim resguardar as capacidades abstratas de orientação moral e as capacidades concretas necessárias para o desenvolvimento de uma vida digna, cercada por respeito endógeno e exógeno, ou seja, é por meio do reconhecimento jurídico que são criadas condições que podem permitir às pessoas com deficiência referir-se de modo positivo sobre si própria, porquanto merecedora do mesmo respeito atribuído aos demais sujeitos sociais.

\begin{abstract}
(...) o autorrespeito é para a relação jurídica o que a autoconfiança era para a relação amorosa é o que já se sugere pela logicidade com que os direitos se deixam conceber como signos anonimizados de um respeito social, da mesma maneira que o amor pode ser concebido como a expressão afetiva de uma dedicação, ainda que mantida à distância: enquanto este cria em todo ser humano o fundamento psíquico para poder nos confiar próprios impulsos carenciais, aqueles fazem surgir nele a consciência de poder se respeitar a si próprio, porque ele merece o respeito de todos os outros (HONNETH, 2003, p. 194-195).
\end{abstract}

$\mathrm{Na}$ esfera do reconhecimento jurídico, dessa forma, ser sujeito de direitos no meio social significa que o indivíduo pode participar do contexto social em iguais condições com demais membros do grupo e contribuir para a ampliação do horizonte normativo das normas morais. No sistema jurídico devem estabelecer interesses universalizáveis de todos os membros da sociedade não admitindo privilégios e gradações, contudo, o que podem variar de acordo com as condições individuais são as formas de acesso ao exercício dos direitos e cumprimento das obrigações.

Se desrespeitada esta segunda esfera do reconhecimento social, na prática haverá prejuízo na formação do autorrespeito, da imputabilidade moral do indivíduo que, consequentemente vai produzir a exclusão ao inviabilizar a posse de determinados direitos atribuídos aos demais sujeitos, atingindo a integridade social enquanto componente da personalidade humana. A contínua negação de alguns desses direitos provoca na pessoa a sensação de rebaixamento moral, pois a reduz na incapacidade de fazer julgamentos morais, que afeta, por consequência, seu autorrespeito. Eis que a negativa do reconhecimento às relações jurídicas corresponde a:

(...) uma perda da capacidade de se referir a si mesmo como parceiro em pé de igualdade na interação com os próximos. Portanto o que aqui é subtraído da pessoa pelo desrespeito em termos de reconhecimento é o respeito cognitivo de uma imputabilidade moral que, por seu turno, tem de ser adquirida a custa de processos de interação socializadora. Mas essa forma de desrespeito representa uma grandeza historicamente variável, visto que o conteúdo semântico do que é considerado como uma pessoa moralmente imputável tem se alterado com o desenvolvimento das relações jurídicas: por isso, a experiência da privação de direitos se 
mede não somente pelo grau de universalização, mas também pelo alcance material dos direitos institucionalmente garantidos (Honneth, 2003, p. 217).

O desrespeito aos direitos que gera exclusão corresponde a uma espécie de "morte social", pois quando não respeitados, exclui a pessoa da convivência coletiva a depreciando em seu próprio respeito (Honneth, 1992, p. 191-192).

\subsubsection{A terceira esfera de reconhecimento:}

Por outro lado, se efetivada a segunda esfera de reconhecimento, explicitada acima, completado estará o ciclo de direitos que visam promover igualdade de oportunidades e será dado espaço à terceira esfera que se dá pela estima social ao deflagrar a formação da autoestima por serem evidenciadas propriedades de singularidade e, dessa forma, possibilitar ao indivíduo tornar-se de modo legítimo diferente dos demais com a devida valorização do direito à diversidade enquanto parte da normalidade e com a ampliação de um pluralismo valorativo que permita reconhecer a concepção individual de vida digna como consequência da esfera anterior que detinha um processo genérico, daí sim se podendo falar em verdadeira inclusão.

Enquanto para o reconhecimento jurídico a perspectiva de debate se dá na forma como se constrói a imputabilidade moral do grupo de indivíduos, na estima social a discussão se concentra na aferição de valor das características particulares e das potencialidades dos mesmos, ou seja, no caso do trabalho e emprego, enquanto para o reconhecimento jurídico seria criar a lei para a generalidade de PcD's, na estima social seria identificar as competências e habilidades dos trabalhadores e valorizá-los.

Honneth (2003, p. 209 ss.) conclui que um padrão de reconhecimento em que haja uma estima mútua vai além dos afetos e da rede jurídica dos direitos, e só se torna compreensível quando implicitamente houver um horizonte de valores partilhados entre si pelos sujeitos envolvidos representados pela solidariedade e pela empatia. A autorrelação prática a que uma experiência de reconhecimento da autoestima proporciona aos indivíduos sintetiza-se no sentimento de orgulho do grupo ou de honra coletiva, na medida em que o “(...) indivíduo se sabe aí como membro de um grupo que está em condições de realizações comuns, cujo valor para a sociedade é reconhecido por todos os seus demais membros. Entretanto, uma pessoa desenvolve a capacidade de sentir-se valorizada quando suas 
capacidades individuais não são mais avaliadas com paradigmas ou referências coletivas, eis que o valor decorre de qualidades e realizações individuais que, ao serem expostas, serão reconhecidas no plano das relações intersubjetivas ou sociais. A estima social representa um sinal claro de aceitação das escolhas, peculiaridades e habilidades do sujeito, com influência direta no aumento da auto-estima pessoal. O princípio da solidariedade permeia essa etapa do reconhecimento, pois pressupõe a aceitação e o encorajamento de estilos de vida não convencionais, em respeito às características próprias e as especificidades biográficas de cada pessoa, bem como a ocorrência de relações simétricas entre os membros do corpo social.

Saavedra \& Sobottka (2008, p. 13) explicam que na vida moderna há um permanente processo de luta porque nesta nova forma de organização social há um embate entre uma busca individual por diversas formas de autorrealização e, de outro, a busca hegemônica de um sistema com avaliação social da moralidade. É nessa tensão social que a interpretação honnethiana entende ser construído um espaço no qual se desenvolve uma luta por reconhecimento, onde a pluralidade de grupos tenta influenciar a vida pública a fim de que cada concepção de vida digna encontre seu respectivo reconhecimento social, e assim seja integrada na normalidade do sistema que elenca as referências morais da comunidade em que estão inseridos, desencadeando, portanto, o surgimento da estima social. Diante disso, segundo Honneth (2003, p. 207):

Nas sociedades modernas, as relações de estima social estão sujeitas a uma luta permanente na qual os diversos grupos procuram elevar, com os meios da força simbólica e em referência às finalidades gerais, $o$ valor das capacidades associadas à sua forma de vida.

Deste modo, esta forma de reconhecimento requer um meio social que situe as diferenças de competências, habilidades e qualidades dos sujeitos dentro do prisma de normalidade com (re)formulação de valores, objetivos éticos e orientações articuladas no sentido de constituir a autocompreensão e o respeito cultural, uma vez que, esta constituição é que predetermina os critérios pelos quais se orienta a estima social dos indivíduos, já que suas capacidades e realizações são julgadas intersubjetivamente conforme haja cooperação com os valores culturalmente definidos. Como lembra Albornoz (2011, p. 140):

Quanto mais as concepções dos objetivos éticos se abrem a diversos valores, e quanto mais a ordenação hierárquica cede a uma concorrência horizontal, tanto mais a estima social assumirá um traço individualizante e criará relações simétricas (...). Assim, tem-se hoje que a afirmação na rede dinâmica da estima social não se faz apenas no registro da dinâmica intersubjetiva e do reconhecimento das capacidades e realizações individuais, mas na 
dinâmica dos grupos que representam formas de vida, como afirmação e conquista de estima social de grupos ou "movimentos sociais". Quanto mais os movimentos sociais conseguem chamar a atenção da esfera pública para a importância das capacidades por eles representadas, de modo coletivo, tanto mais existe a possibilidade de elevar na sociedade o valor social do grupo que representam - dito de outro modo, elevar a reputação de seus membros. (...)

Por todo o exposto, esta terceira esfera ao guardar estreita relação com habilidades, competências e desempenho na contribuição para o bem-estar social (HONNETH, 2003, p. 186-188), apresenta uma forte ligação com o mundo do trabalho (BONFIM, 2009, p. 20).

Destaca-se que, se o desrespeito atinge esta terceira esfera do reconhecimento recíproco, a formação da autoestima resta comprometida por desencadear degradação e ofensa à formação e atribuição de um valor social da pessoa e, consequentemente, a subtração do "assentimento social a uma forma de autorrealização que ela encontrou arduamente como o encorajamento baseado em solidariedades de grupos" (HONNETH, 2003, p. 218), ou seja, há prejuízo na honra e na dignidade dos sujeitos que não se enxergam merecedores da estima social. Esse tipo de insulto pode ser entendido como o resultado da ofensa e do sofrimento causados pelo desprezo social por terem considerados de menor valia determinadas características corporais (como o caso das pessoas com deficiência), ou costumes, culturas, crenças, impedindo, então, a autorrealização no meio coletivo.

\section{EM QUAL ESFERA DE RECONHECIMENTO O BRASIL SE ENCONTRA?}

Como seres humanos, precisamos ser reconhecidos através de cada um dos três processos e formas de reconhecimento efetivo para assim estabelecer relações positivas nos termos de "autoconfiança", "autorrespeito" e "autoestima". É imperioso destacar que as formas de desrespeito ou não-reconhecimento gera uma dualidade, pois, ao mesmo tempo em que pode ser o impulso que motiva aos sujeitos à luta por reconhecimento social, haja vista a tensão afetiva deflagrada por humilhações que impede o indivíduo de autorrealizar-se, de aprimorar todas as suas habilidades, também força os indivíduos a entrarem numa luta próativa em prol da dissolução do bloqueio de reconhecimento com a consequente possibilidade de realização por meio da inclusão no mundo da vida social em geral (Ibidem, p. 224), espaço onde até então eram considerados “meros objetos insensíveis” (HONNETH, 2008a, p. 57).

É importante destacar, contudo, que a base empírica fenomenológica honnethiana identifica que nem todas as esferas de reconhecimento contêm uma tensão moral que possa desencadear conflitos sociais haja vista que, para tornar-se luta social, as demandas tem que 
ultrapassar o horizonte dos objetivos individuais e tornar-se base de objetivos coletivos. Posto isso, o reconhecimento por meio do amor (primeira esfera), em que pese esteja inserido em uma dimensão existencial de luta, não contém experiências morais que resultem na formação de conflitos sociais. E, portanto, as formas de reconhecimento do direito e da estima social é que são representantes do quadro moral que pode gerar conflitos sociais já que se baseiam em critérios socialmente generalizados haja vista que "as experiências pessoais de desrespeito podem ser interpretadas e apresentadas como algo capaz de afetar potencialmente também outros sujeitos" (Ibidem, p. 256).

Diante desta fundamentação, Honneth conclui que "as experiências individuais de desrespeito são interpretadas como experiências cruciais típicas de um grupo inteiro, de forma que elas podem influir (...) na exigência coletiva por relações ampliadas de reconhecimento" (Idem, p. 257) por parte da comunidade de modo que, quanto maior a capacidade do meio social em reconhecer positivamente o grupo ao tornar-se mais inclusivo, mais será gerada a autorrealização positiva das identidades pessoais a qual o indivíduo, portanto, referir-se-á a si mesmo como sujeito (Idem, p. 272).

Para inúmeras pessoas com deficiência, a primeira esfera de reconhecimento é mais ou menos permanentemente presente nas relações com assistentes e cuidadores ao envolverem a questão da integridade e questões relacionadas à autonomia, dependência e apoio. A segunda esfera permite que o processo de reconhecimento através da lei desenvolva o "auto-respeito" entre os indivíduos com e sem deficiência. Por fim, a terceira categoria de reconhecimento apresenta forte ligação com o mundo do trabalho (BONFIM, 2009) no que tange à questão da estigmatização de Goffman (2008), que pode ser entendida como um processo em que a avaliação negativa de uma característica dentro de uma "ordem moral local" faz com que as pessoas com essa característica, por exemplo, desenvolvam estratégias para proteger sua "auto-estima".

No Brasil, a exemplo dos Estados Unidos e do Reino Unido ${ }^{11}$, o momento social acerca da inclusão das pessoas com deficiência se encaixa, regra geral, na segunda esfera do

\footnotetext{
${ }^{11}$ Interessante abordagem faz Bonfim (2009, p. 141-143) ao destacar os momentos sociais vivenciados pelos Estados Unidos e Reino Unido, de acordo com as esferas de reconhecimento de Axel: "Nos Estados Unidos, país considerado paradigmático no reconhecimento e implementação dos direitos das pessoas com deficiência, verificam-se situações de retrocesso, a exemplo do que ocorreu com a interpretação restritiva da definição de deficiência constante do ADA (Lei dos americanos sobre deficiência - Americans with Disabilities Act), o que levou à recente aprovação, em 2008, de uma emenda à referida lei, com o intuito de restabelecer a intenção original do legislador. Nesse ponto, merece espaço uma reflexão sobre o posicionamento do congresso americano e da suprema corte quanto ao processo de reconhecimento dessa categoria. Enquanto a primeira
} 
reconhecimento, pois ainda aparenta estar na fase de um debate intenso pela igualdade de direitos do grupo. Cumpre reconhecer que, não obstante tenha sido conquistada uma extensa legislação protetiva, tanto o Estatuto da Pessoa com Deficiência (Lei n ${ }^{\circ}$ 13.146/2015) destinado a assegurar e a promover, em condições de igualdade, o exercício dos direitos e das liberdades fundamentais da pessoa com deficiência, visando à sua inclusão social e cidadania, como também a "Lei de Cotas" (Lei no 8.213/1991) que visa a reserva de vagas para pessoas com deficiência no mercado de trabalho.

Porém, tem-se que a concretização da igualdade ainda enfrenta desafios em sua implementação, pois as políticas públicas voltadas para a consecução dos vários objetivos efetivam-se de forma lenta, parcial e muitas vezes desrespeitosa. Para que as leis alcancem a

instituição mostra-se sensível às demandas por concretização de direitos formalmente garantidos, tanto o é que optou por reafirmar, também por meio do processo legislativo, as motivações que embasaram a aprovação do ADA, a suprema corte age na direção contrária, sinalizando para a dificuldade de aceitação da proteção social oferecida a esse grupo por meio de legislação específica. Como assevera Honneth, o processo de reconhecimento intersubjetivo comporta também esses retrocessos, uma vez que exige uma mudança nas percepções culturais sobre a questão. Em geral, o reconhecimento formal das demandas de grupos minoritários não caminha pari passu com o reconhecimento substantivo, que necessita de um trabalho percuciente de conscientização, tanto do grupo oprimido como da maioria, da necessidade substantiva de mudança de paradigma. À militância política, como ocorre com frequência nos Estados Unidos, cabe utilizar os instrumentos legais disponíveis para fazer valer as disposições legais. Ainda sobre o movimento americano, cabe destacar que Longmore (2003) assevera que esse movimento representativo encontra-se em uma segunda fase, qual seja, a luta pelo reconhecimento da cultura própria de vários grupos de deficientes nos EUA. Na perspectiva de Honneth, essa etapa da luta pelo reconhecimento seria de terceira ordem, pois visa a aceitação comunitária das peculiaridades grupais, em uma relação simétrica com os demais membros da coletividade. Todavia, não se considera possível afirmar que a segunda etapa do reconhecimento foi concluída com sucesso nesse país, haja vista a necessidade de o próprio congresso americano reafirmar formalmente a garantia do direito a não discriminação em razão da deficiência então assegurada pelo ADA, em 1990. Se a própria suprema corte americana adota uma postura conservadora em relação à concretização dos direitos civis desse segmento populacional, é razoável supor que outras instituições, bem como a população em geral, ainda oscilem em incorporar o novo paradigma e deixem vir à tona atitudes estigmatizantes, preconceituosas e discriminatórias, historicamente dirigidas às pessoas com deficiência. Por seu turno, o movimento britânico encontra-se também na segunda ordem do reconhecimento. Não obstante o desenvolvimento de um arcabouço teórico consistente, que serviu de base na luta para a inclusão da deficiência na arena política daquele país, as conquistas efetivas, no sentido do reconhecimento formal de suas demandas, ocorreram de forma mais lenta do que nos Estados Unidos, haja vista que o British Disability Discriminaction Act - DDA só foi aprovado em 1995. De acordo com Swain; French; Cameron (2003, p. 158-159), o texto aprovado não é tão enfático na proibição da discriminação em razão da deficiência nem provê os meios de coibila, como outras legislações atinentes à proibição de discriminação de grupos minoritários, a exemplo do Sex Discrimination Act e o Race Relactions Act. Na percepção de Gooding sobre o DDA (apud Swain et al., 2003, p. 159), para que essa lei ganhe reconhecimento, é preciso, acima de tudo, mudança ampla nos valores culturais relacionados aos deficientes - uma mudança de paradigma nos modos em que a deficiência é entendida pela sociedade. O paradoxal dessa história é que o referido DDA foi construído dentro do modelo social de deficiência, mas permanece preso ao modelo médico/individual de deficiência dominante. Em que pese as poucas informações da literatura sobre o assunto, um sinal de que a terceira etapa do processo de reconhecimento honnethiano vem se desenvolvendo, no Reino Unido, é dado pela adoção dos direct payments à pessoas com deficiência que necessitam de auxílio para realização de tarefas cotidianas, como higiene pessoal e serviço doméstico. Essa conquista do movimento permite que as pessoas com deficiência façam suas próprias escolhas e que essas sejam respeitadas pela comunidade, no lugar de aceitarem os cuidadores indicados pelos orgãos governamentais ou entidades beneficentes, que muitas vezes não respeitavam a privacidade do tomador do serviço ou suas preferências. 
terceira esfera do reconhecimento, é preciso, acima de tudo, mudança ampla nos valores culturais e nos paradigmas relacionados à associação com a incapacidade com que a deficiência é entendida pelo mundo empresarial, pelo capital e, também pela sociedade.

\section{CONSIDERAÇÕES FINAIS:}

Pelo exposto, verifica-se que para se alcançar a liberdade plena como cidadão reconhecido socialmente há um processo de maturação composto primeiramente pela esfera das relações afetivas (a primeira que passará para o "lado de fora" e que concretizará a primeira vertente do reconhecimento), seguida da esfera das relações jurídicas e finalmente a esfera das relações de estima social, ambas com as consequências já apresentadas. Constata-se que eventuais fatores de desrespeito às esferas podem bloquear a passagem das mesmas rumo ao pleno reconhecimento dos sujeitos.

Conclui-se que a Lei de Cotas como reconhecimento jurídico conduz a uma certa inclusão da pessoa com deficiência no mercado de trabalho, porém, ainda há desafios e perspectivas que conduzam à inclusão real como condição ao reconhecimento integral dos indivíduos. Parece ser necessária a cobrança eficaz de medidas que garantam o respeito à diversidade como atributo da igualdade a começar com a insistência de manter a desconstrução de barreiras atitudinais implementadas culturalmente a partir de uma longa tradição de preconceitos e discriminações em relação às pessoas com deficiência. Com isso, parece que haverá uma proximidade entre o reconhecimento formal e o reconhecimento substantivo. Não basta a lei garantir o emprego (e assim ascender à segunda esfera do reconhecimento). É preciso (des)construir o olhar social.

Desenvolver o reconhecimento das pessoas com deficiência em plenitude, para que se possa falar em inclusão em seu sentido real, demanda o fato de, já reconhecidos juridicamente, todos os atores sociais poderem experimentar e compartilhar atitudes e atributos nas interações sociais e serem retribuídos por outros sujeitos da comunidade, gerando um respeito mútuo dentro de uma teia complexa de relação que mais se aproxima do proposto pela abordagem relacional da deficiência.

Para a construção da justiça social, o reconhecimento parece ser um mecanismo promissor principalmente para o âmbito desta pesquisa quando escolhe o universo do trabalho, já que viabiliza um melhor entendimento dos dilemas decorrentes do 
multiculturalismo nas sociedades contemporâneas; freia os desrespeitos produzidos hegemonicamente; propicia a afirmação dos direitos humanos e a efetividade dos direitos fundamentais; contribui para a formação saudável da identidade do sujeito e da coletividade a qual o mesmo está inserido; propicia a compreensão efetiva dos efeitos das políticas públicas inclusivas.

\section{REFERÊNCIAS BIBLIOGRÁFICAS:}

ABBERLEY, P. The concept of oppression and the development of a social theory of disability. Disabil, Handicap Soc, v. 2, n. 1, p. 5-21, 1987.

ALBORNOZ, S. G. As esferas do reconhecimento: uma introdução a Axel Honneth. Cadernos de Psicologia Social do Trabalho, v. 14, n. 1, p. 127-143, 2011.

ALBRECHT, G. L.; SEELMAN, K. D.; BURY, M. Handbook of disability studies. Thousand Oaks, CA: Sage, 2001.

BOBBIO, N. A era dos direitos. Rio de Janeiro: Campus, 1992.

BONFIM, S. M. M. A luta por reconhecimento das pessoas com deficiência: aspectos teóricos, históricos e legislativos. Rio de Janeiro: Dissertação (Mestrado em Ciência Política) - Instituto Universitário de Pesquisas do Rio de Janeiro e ao Centro de Formação, Treinamento e Aperfeiçoamento da Câmara dos Deputados, 2009.

Lei 13.146, 06 de julho de 2015. Institui a Lei Brasileira de Inclusão da Pessoa com Deficiência (Estatuto da Pessoa com Deficiência). Disponível em: < http://www.planalto.gov.br/ccivil_03/_ato2015-2018/2015/lei/113146.htm>. Acesso em: 20 abril 2020

Lei 8.213, 24 de julho de 1991. Dispõe sobre os planos de benefícios da previdência social e dá outras providências. Disponível em: < http://www.planalto.gov.br/ccivil_03/leis/18213cons.htm>. Acesso em: 20 abril 2015.

FERRAJOLI, L. Los fundamentos de los derechos fundamentales. Madrid: Trotta, 2009.

FRASER, N.; HONNETH, A. Redistribution or recognition? a political-philosophical exchange. New York: Verso, 2003.

GIL, Antonio Carlos. Métodos e técnicas de Pesquisa Social. 6. ed São Paulo: Atlas. 2008.

GOFFMAN, E. Estigma: notas sobre a manipulação da identidade deteriorada. Rio de Janeiro: LTC, 2008.

GUGEL, M. A. A pessoa com deficiência e sua relação com a história da humanidade. Disponível em: <http://www.ampid.org.br/ampid/Artigos/PD_Historia.php>. Acesso em: 1 set. 2015 . 
HARRIS, A.; ENFIELD, S. Disability, equality, and human rights. a training manual for development and humanitarian. UK: Osfam, 2003.

HONNETH, A. Integrity and Disrespect. Principles of a conception of morality based on the theory of recognition. Political Theory, v. 20, n. 2, p. 187-201, 1992.

HONNETH, A. Luta por reconhecimento: a gramática moral dos conflitos sociais. trad. luís repa. São Paulo: Editora 34, 2003.

LONGMORE, P. K. Why i burned my book and other essays on disability. US: Temple University Press, 2003.

MARMELSTEIN, G. Curso de direitos fundamentais. São Paulo: Atlas, 2008.

MARSHALL, T. H. Sociology at the crossroads and other essays. London: Heinemann, 1963.

.Cidadania, classe social e status. Rio de Janeiro: Zahar Editores, 1967.

MATTOS, P. A sociologia política do reconhecimento: as contribuições de charles taylor, axel honneth e nancy fraser. São Paulo: Annablume, 2006.

MEAD, G. . H. Espiritu, persona y sociedad. Barcelona: Paidós, 1973.

MENEZES, J. B. de. Tomada de decisão apoiada: instrumento de apoio ao exercício da capacidade civil da pessoa com deficiência instituído pela lei brasileira de inclusão (lei n. 13.146/2015). Revista Brasileira de Direito Civil, v. 9, p. 31-57, 2016.

REQUIÃO, M. As mudanças na capacidade e a inclusão da tomada de decisão apoiada a partir do estatuto da pessoa com deficiência. Revista dos Tribunais Online, v. 3, p. 37-54, 2016.

SAAVEDRA, G. A.; SOBOTTKA, E. A. Introdução à teoria do reconhecimento, de Axel Honneth. Civitas Revista de Ciências Sociais, v. 8, n. 1, p. 9-18, 2008.

SILVA, O. M. da. A epopéia ignorada - a pessoa deficiente na história do mundo de ontem e de hoje. São Paulo: CEDAS, 1987.

SWAIN, J.; FRENCH, S.; CAMERON, C. Controversial issues in a disabling society. London: Open University Press, 2003.

TREMAIN, S. Foucault and the governmentaliy of disability. Ann Arbor: University of Michigan, 2005.

WINNICOTT, D. W. Reifungsprozesse und fördernde umwelt: studien zur theorie der emotionalen entwicklung. Frankfurt: Fischer-Taschenbuch-Verlag, 1984. 